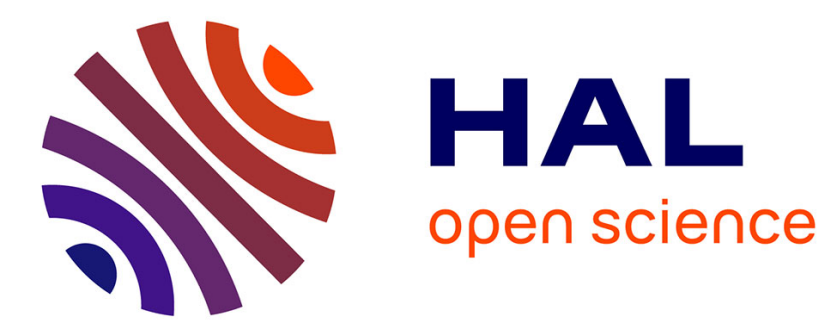

\title{
Aerodynamic Characterization of an Off-the-Shelf Aircraft via Flight Test and Numerical Simulation
}

Murat Bronz, Gautier Hattenberger

\section{To cite this version:}

Murat Bronz, Gautier Hattenberger. Aerodynamic Characterization of an Off-the-Shelf Aircraft via Flight Test and Numerical Simulation. AIAA Flight Testing Conference 2016, Jun 2016, Washington, United States. pp.E-ISBN:978-1-62410-431-2, 10.2514/6.2016-3979 . hal-01333870

\section{HAL Id: hal-01333870 \\ https://hal-enac.archives-ouvertes.fr/hal-01333870}

Submitted on 27 Jun 2016

HAL is a multi-disciplinary open access archive for the deposit and dissemination of scientific research documents, whether they are published or not. The documents may come from teaching and research institutions in France or abroad, or from public or private research centers.
L'archive ouverte pluridisciplinaire HAL, est destinée au dépôt et à la diffusion de documents scientifiques de niveau recherche, publiés ou non, émanant des établissements d'enseignement et de recherche français ou étrangers, des laboratoires publics ou privés. 


\title{
Aerodynamic Characterization of an Off-the-Shelf Aircraft via Flight Test and Numerical Simulation
}

\author{
Murat Bronz* and Gautier Hattenberger ${ }^{\dagger}$ \\ ENAC, F-31055 Toulouse, France \\ University of Toulouse, F-31400 Toulouse, France
}

\begin{abstract}
Characterization of an off-the-shelf small tailless aircraft with a wing span of $1.3 \mathrm{~m}$ is presented. Mentioned aircraft is being used in several scientific measurement projects by authors, whereas the flight performance and quality such as endurance, and stability plays an important role on the measurement quality. Hence the main objective is to use the extracted and fine tuned aerodynamic and flight performance characteristics of the aircraft for a better flight control and mission planning during simulations and real flights. Aerodynamic characteristics are obtained through flight tests, numerical analyses, and some isolated ground experiments for the propulsion system. The comparison of different measurement and estimation techniques are discussed.
\end{abstract}

\section{Introduction}

The use of small Unmanned Air Vehicles (UAVs) in atmospheric research has increased because of their compact size and ease of operation. However, their relatively lower performance compared to bigger UAVs highly limits the endurance, range, and payload capabilities. Optimization of the airframe specifically according to the mission profile can result in big gains in flight performance and quality of the UAV as presented by Bronz and Hattenberger. If the modification of the aircraft that is being used for the mission is not possible, then selection of the propulsion system and the on-board energy becomes critical. Several work are presenting identification techniques for small or larger UAVs. ${ }^{2-4}$ In most cases, the goal

*Assistant Professor on Applied Aerodynamics, ENAC UAV Lab, MAIAA, F-31055 Toulouse, France

${ }^{\dagger}$ Assistant Professor on Flight Dynamics, ENAC UAV Lab, MAIAA, F-31055 Toulouse, France 
is to produce a state space model directly usable for applying advanced control theory, hence focusing on the dynamics. The work from Edwards ${ }^{5}$ proposes a simple and practical methods to extract lift and drag coefficients from flight tests based on gliding phases analysis. This approach will be the starting point of this current study.

\section{A. Present Work}

This study focuses on improving the aerodynamic characterization methods for a small UAV, by using both numerical analyses, ground experiments and flight test. Additionally, the onboard thrust measurements will shed a light on the propeller and fuselage wake interaction mechanism, as it will be possible to compare the bare propeller thrust generation inside the wind tunnel and during the flight behind the fuselage wake. Selected aircraft specifications and all of the on-board sensors will be presented on the first section, following the experimental setup and results including the methods used for measurements. Afterwards, the numerical analysis methods and results will be presented, finishing with a section on the comparison of obtained results on aerodynamic characteristics of the aircraft.

\section{Aircraft Presentation and Instrumentation}

The aircraft selected for characterization is an off-the-shelf frame commercially available for recreational use. General specifications of the aircraft is given in Table 1 . It is made up of Elapor foam material, which makes it light weight and easy to repair, however it also limits the maximum take-off mass and the flight velocity because of limited strength. Take-off mass and the flight velocity are given mainly according to the mentioned reason on aircraft's structural prop-

\begin{tabular}{lcl} 
Wing Span & 1.288 & {$[\mathrm{~m}]$} \\
Wing Surface Area & 0.27 & {$\left[\mathrm{~m}^{2}\right]$} \\
Mean Aero. Chord & 0.21 & {$[\mathrm{~m}]$} \\
Electric Motor & AXI 2212/26 & \\
Prop Diameter & 0.228 & {$[\mathrm{~m}]$} \\
Take-off Mass & $0.7-2.0$ & {$[\mathrm{~kg}]$} \\
Flight Velocity & $10-25$ & {$[\mathrm{~m} / \mathrm{s}]$} \\
\hline
\end{tabular}

Table 1. General specifications of the Aircraft. erties.

\section{A. Autopilot and Sensors}

The Apogee a autopilot board running the Paparazzi Autopilot System, ${ }^{6,7}$ is used for all the experimental flights. The Paparazzi is a well known and proven open-source and openhardware system, used by hundreds of individual user around the world.

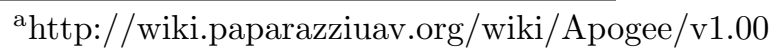


The Apogee board has 3-axis gyroscope, accelerometer, magnetometer (MPU-9150), and a low-resolution barometer (MPL-3115A2). A GPS receiver module (Ublox-NEO-M8N) is added externally.

A dedicated hardware called Meteo-Stick ${ }^{\mathrm{b}}$ is used for some external sensors, such as absolute pressure and differential pressure for airspeed. It has high resolution (24bit) analog to digital converters. An angle of attack sensor have been built with an absolute angular position sensor and a simple vane. The angular sensor used is the model MA3-P12-125-B from US DIGITAL ${ }^{c}$. It is using hall effect with 12-bit internal converter giving less than $0.09^{\circ}$ of resolution with a very low noise. The wind vane is $3 \mathrm{D}$-printed and mounted directly on to the shaft of the sensor. The Figure 1 shows the final integration of this two sensors to the nose of the fuselage. The piece holding them has also been build by a 3D printer. All sensors are connected to the Apogee board which is also used as a data acquisition board (DAQ) as it includes a SD card slot for high speed logging.

Previously a separate current sensor was being used to measure the electrical current drown by the motor for the first flights, but it is replaced by the ESC32 v3.0 electronic speed controller as it has an internal current sensor and outputs the current measurement from serial connection. This new speed controller also outputs the RPM of the motor and the voltage average on the motor phases. These additional informations will be used for an on-board characterization effort during flight tests for future work.

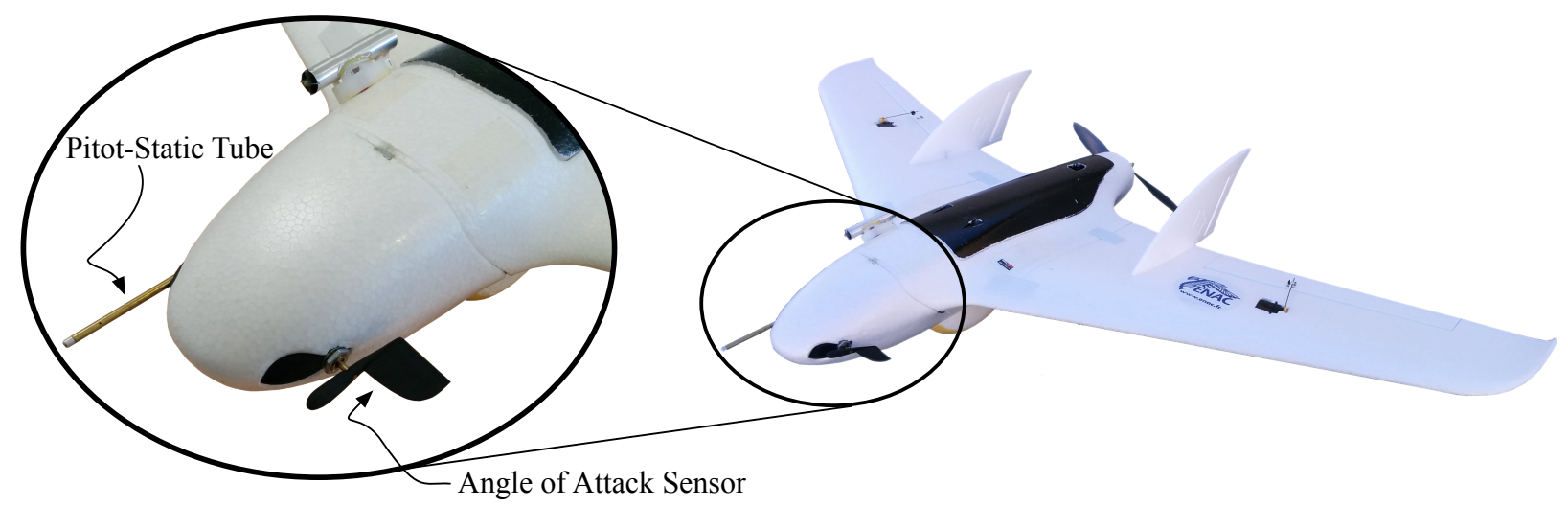

Figure 1. Integration of the pitot-static airspeed tube and the angle of attack sensor on the nose of the aircraft.

\section{B. Sensor Calibration}

All of the sensors that are used on the aircraft requires calibration. The on-board IMU of the Apogee board is calibrated by the in-house written scripts of Paparazzi Autopilot System. The airspeed sensor and the angle of attack sensor is calibrated in the wind-tunnel of ENAC.

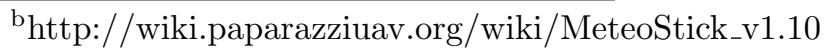

${ }^{c}$ http://www.usdigital.com/products/encoders/absolute/rotary/shaft/ma3
} 
The main reason of angle of attack sensor calibration is the influence of the fuselage.

\section{Electric Propulsion System Identification}

Motor and propeller characteristics need to be identified in order to be used afterwards for the aerodynamic characterization of the aircraft during cruise flight. A propulsion test bench is used for characterization of the electric motor and propeller mounted on the aircraft. The objective is to find a relationship between the input electrical power, which is easily measured on-board the aircraft, and the aerodynamic propulsive power (Thrust $\times$ Velocity).

Figure 2 shows the propulsion test bench. Two force sensors, SMD S-100 ${ }^{\mathrm{d}}$, are used to measure the propulsive force and the motor torque. The same ESC32v3 speed controller is used for controlling the rotation speed of the brush-less motor and recording the voltage, current, and motor rotation speed data through its serial connection.
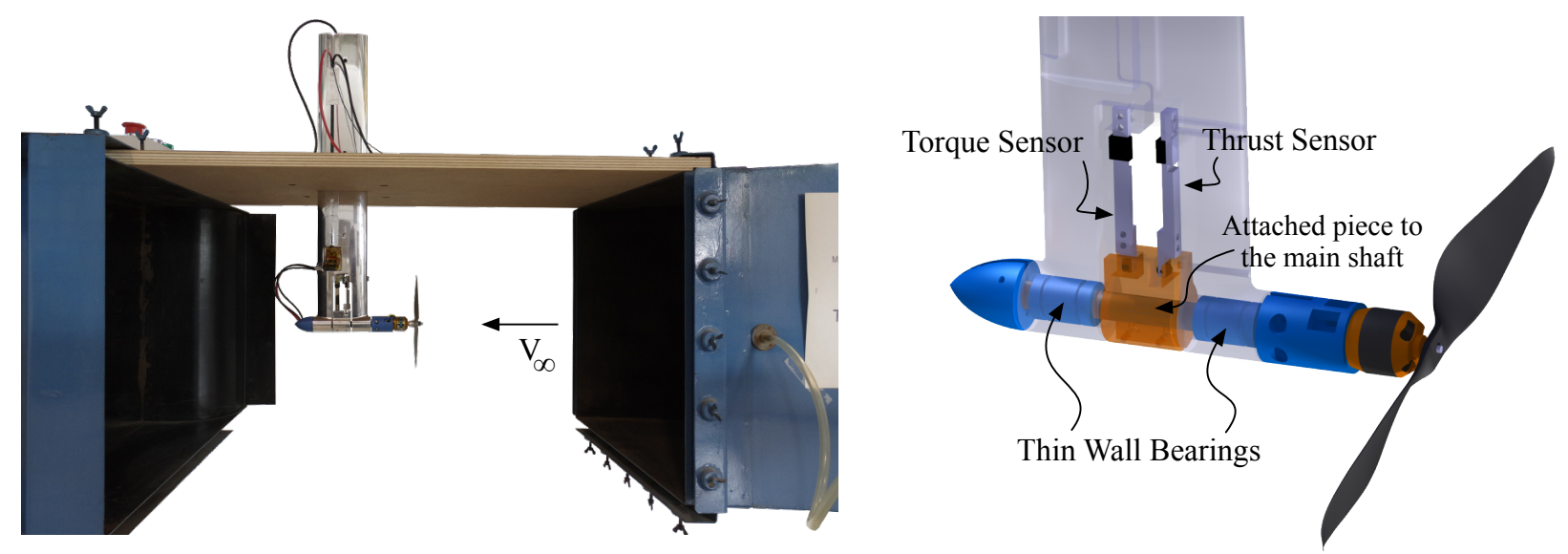

Figure 2. On the left, propulsion test bench mounted in the wind tunnel of ENAC, and on the right a detailed CAD view of the sensor integration and the moving parts is shown.

In addition to the mechanical mounting of the motor and its propeller, an electronic board is required for the sensor signal conditioning. A graphical interface is developed in Python language, which allows to control the motor PWM command and synchronize all the measurements and filter, making the process almost fully automated for the user (the wind tunnel speed is currently controlled by hand).

Additionally, as an on-going work, an on-board force sensor is integrated to the motor mount in order to measure the thrust force during the flight. In an ideal cruise condition without acceleration on any axis, the thrust force measurements will give directly the total drag force of the aircraft at that flight speed. The mounting of the sensor and the motor mount mechanism is shown in Figure 3.

\footnotetext{
${ }^{\mathrm{d}}$ www.smdsensors.com
} 


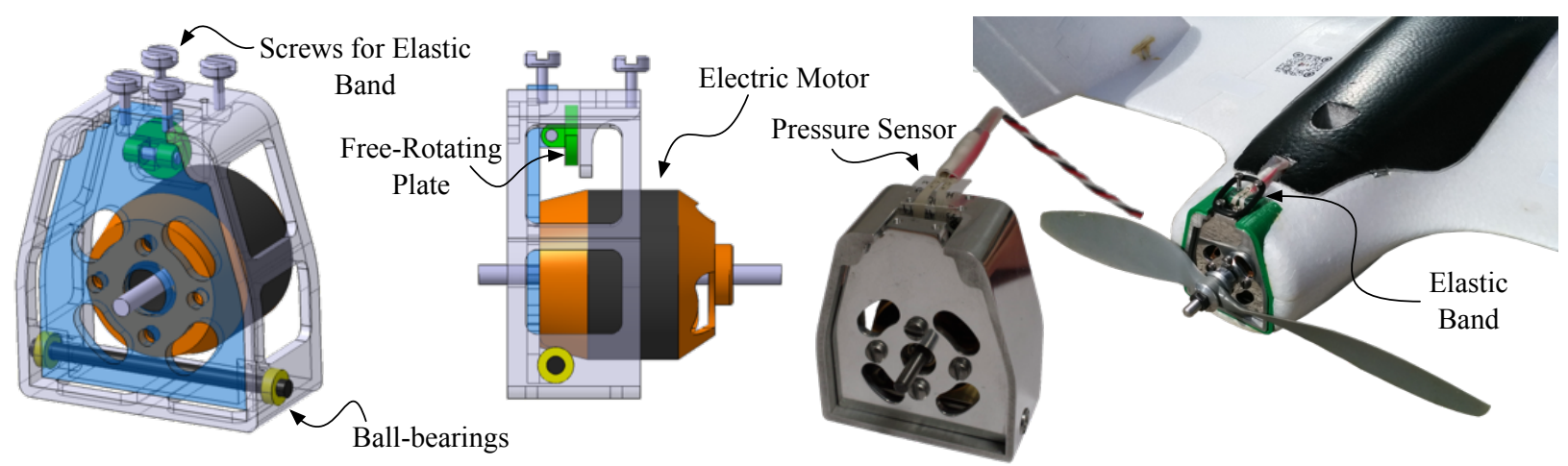

Figure 3. Developed mechanism for the on-board thrust force measurements is shown, starting from left to right with isometric and side CAD drawing views, CNC-manufactured real piece and its integration to the test aircraft.

\section{Experimental Results}

For the characterization of the aircraft, flight conditions can be selected as steady level flight without wind and side slip. Then the effect of control surfaces on the drag coefficient can be neglected for the simplification, which reduces the lift and drag force equations to:

$$
\begin{array}{r}
\mathbf{L}=\frac{1}{2} \cdot \rho \cdot V_{a}^{2} \cdot S_{\mathrm{ref}}\left(C_{L 0}+C_{L \alpha} \cdot \alpha\right) \\
\mathbf{D}=\frac{1}{2} \cdot \rho \cdot V_{a}^{2} \cdot S_{\mathrm{ref}}\left(C_{D 0}+C_{D k} \cdot C_{L}^{2}\right)
\end{array}
$$

In steady level flight, the weight is equilibrated by the lift, and the drag by the thrust. As a first approximation, the thrust, or more precisely the propulsive power $\mathbf{P}$ (the product of the thrust $\mathbf{T}$ by the airspeed $V_{a}$ ) can be expressed as:

$$
\mathbf{P}=\eta \cdot P_{\text {elec }}
$$

where, $P_{\text {elec }}$ is the electrical power drown from the batteries and $\eta$ is an efficiency coefficient, function of the advance ratio, propeller and motor characteristics, Reynolds number and electrical efficiency of the global propulsion system. A more complex propulsion model, ${ }^{8}$ with a first order DC motor model, might be used in later studies in order to define an analytic description of $\eta$.

The procedure described in ${ }^{5}$ have been used. It consists of performing several gliding phases at different airspeed and angle of attack in order to estimate the drag from the glide flight path $\gamma$ :

$$
\tan \gamma=-\frac{\mathbf{D}}{\mathbf{L}}=-\frac{C_{D}}{C_{L}}
$$

The identification of the lift coefficient is done using Eq. 1. For each flight phase, the 
airspeed $V_{a}$ and the angle of attack $\alpha$ are averaged. Then a linear regression is used to estimate the two parameters $C_{L 0}$ and $C_{L \alpha}$.

In order to identify the drag coefficient, only the gliding phases are considered as stated above and equations 2 and 4 are used. Three parameters are then needed, the lift coefficient and the angle of attack that are already computed, and the flight path angle $\gamma$. Since this angle can't be directly measured, two methods have been evaluated. The first method is using an angle of attack sensor installed on the UAV and the pitch angle $\theta$ estimated using the IMU sensor. With the kinematic relation $\theta=\alpha+\gamma$, the path angle is estimated by averaging over the complete phase. The second method is using the relation that the lift over drag ratio is also the ratio between the horizontal distance and altitude lost during a glide. The main constraint is that the experiment needs to be done with almost no wind so that the ground and aerodynamic flight paths are the same. After estimating the parameter $\gamma$, the drag coefficient is computed with Eq. 4, and second order polynomial regression is done between $C_{D}$ and $\alpha$ in order to estimate $C_{D 0}, C_{D k}$.

\section{A. Flight tests}

Several flight tests using the experimental setup described in the previous section have already been conducted. Analyses continues, while the procedure is being improved and modified according to the obtained results. Some preliminary results have been analyzed in order to verify the quality of the angle of attack sensor measurements. The Figure 4 shows the good correlation between the variation of the airspeed and the angle of attack (one increasing when the other decrease). Note that the study uses angle of attack data collected with a constant offset which can be removed from raw data.

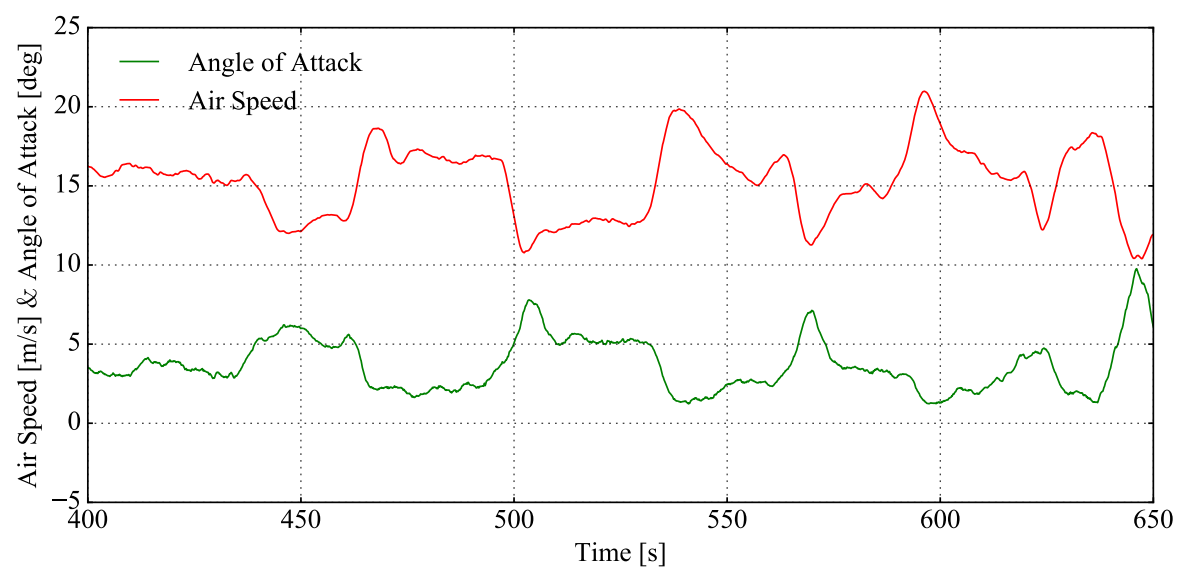

Figure 4. Comparison of the angle of attack (green line) and the airspeed (red line).

Estimation of the lift and drag coefficients as a function of the angle of attack is realized 
by doing several gliding phases at different airspeed. This procedure was explained by Edwards. ${ }^{5}$ The figure 5 is showing four of these flight phases extracted from the complete experimental flight.

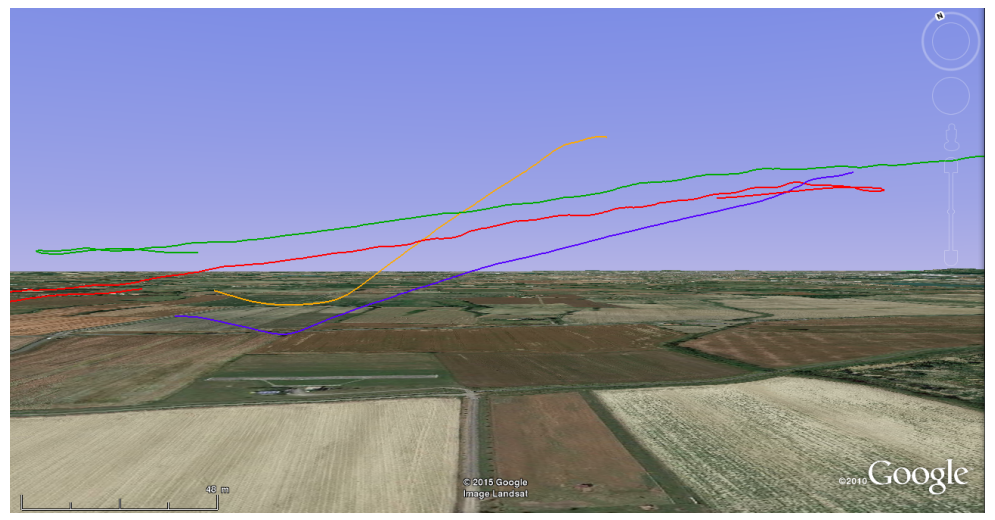

Figure 5. Different gliding flight paths.

From the complete flight, four gliding phases and three cruise level flight phases have been selected for their stable airspeed. Figure 6 (left) shows the lift coefficient $C_{L}$ versus the angle of attack $\alpha$ of the aircraft, according to the data coming from both cruise and gliding phases. Table 2 summarizes the estimated aerodynamic coefficients (with $\alpha$ in degrees).

Regarding the drag coefficient $C_{D}$, it can be seen that the two methods gives fairly different results. The reason for this is that the wind has a strong impact on the second method. The weather conditions on the day of the experiment were favorable with low wind speed on the ground, but it appears at post-processing that it was much stronger even at 100 meters above the ground. As a result, the glide slope is greatly overestimated (head-wind), thus this method will not be considered for the rest of the paper. Nevertheless, the results are coherent and improved flight procedures could be used to remove the effect of the wind in future experiments. Finally, Figure 6 (right) shows the drag coefficient $C_{D}$ versus $C_{L}{ }^{2}$ computed with the first method as described previously. The fitting of the linear curve gives the estimation of the drag parameters as reported in Table 2.

\begin{tabular}{|c|c|c|}
\hline \multirow{3}{*}{$\begin{array}{c}C_{L 0} \\
-0.047 \\
\end{array}$} & \multicolumn{2}{|c|}{$C_{L \alpha}$} \\
\hline & 0.0638 & \\
\hline & $C_{D 0}$ & $C_{D k}$ \\
\hline method 1 & 0.02313 & 0.1897 \\
\hline method 2 & 0.04353 & 0.2284 \\
\hline
\end{tabular}

Table 2. Identified aerodynamic coefficients for lift and drag. 

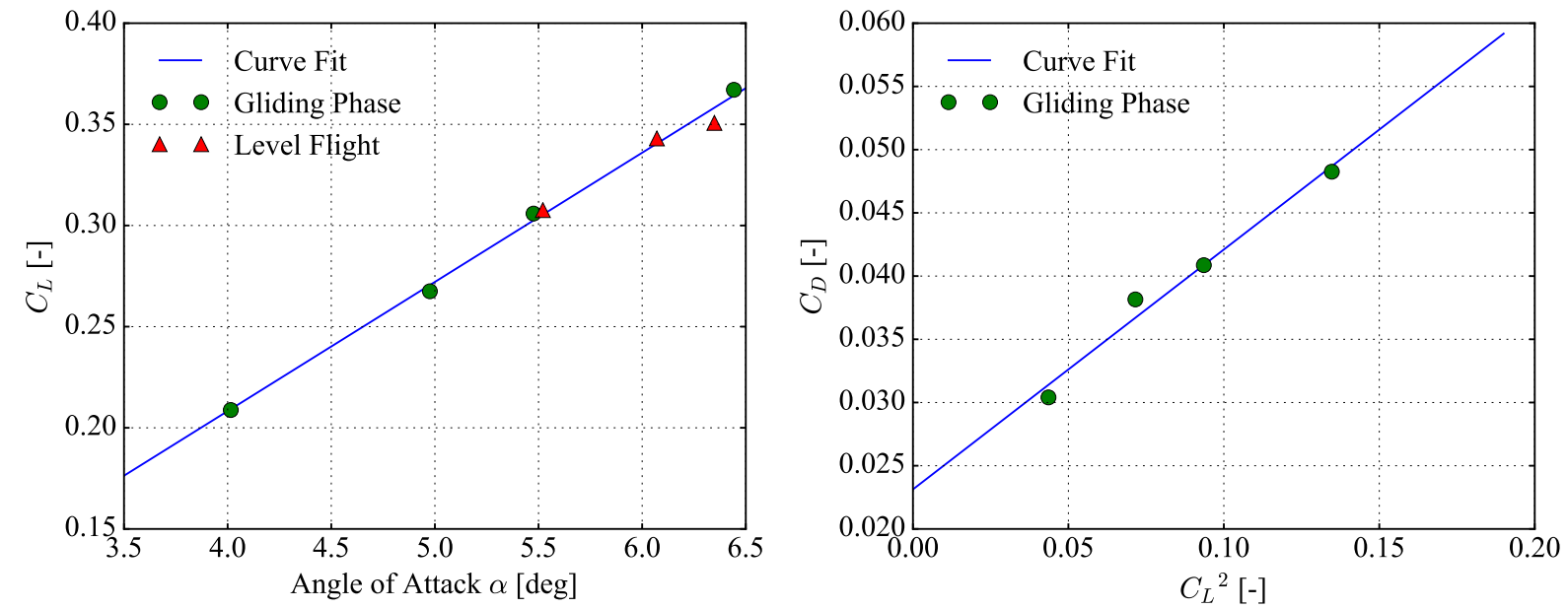

Figure 6. Lift coefficient versus angle of attack, and drag coefficient versus squared lift coefficient, estimated with the first method.

\section{B. Propulsion System Identification}

The propulsion test bench have been placed in a wind tunnel and the parameters have been recorded at different airspeed from $0 \mathrm{~m} / \mathrm{s}$ (static thrust) up to $20 \mathrm{~m} / \mathrm{s}$. The resulting thrust versus RPM is shown on Figure 7. Maximum thrust at static condition is about $6 \mathrm{~N}$ and reduces down to $3 \mathrm{~N}$ at $20 \mathrm{~m} / \mathrm{s}$ flight speed. It can be seen that at higher speed, the motor is not generating positive thrust at low RPM values (at $20 \mathrm{~m} / \mathrm{s}$ it needs at least $70 \%$ of throttle) since the pitch of the propeller and the RPM at that throttle is not sufficient to have a positive local angle of attack on the blade section.
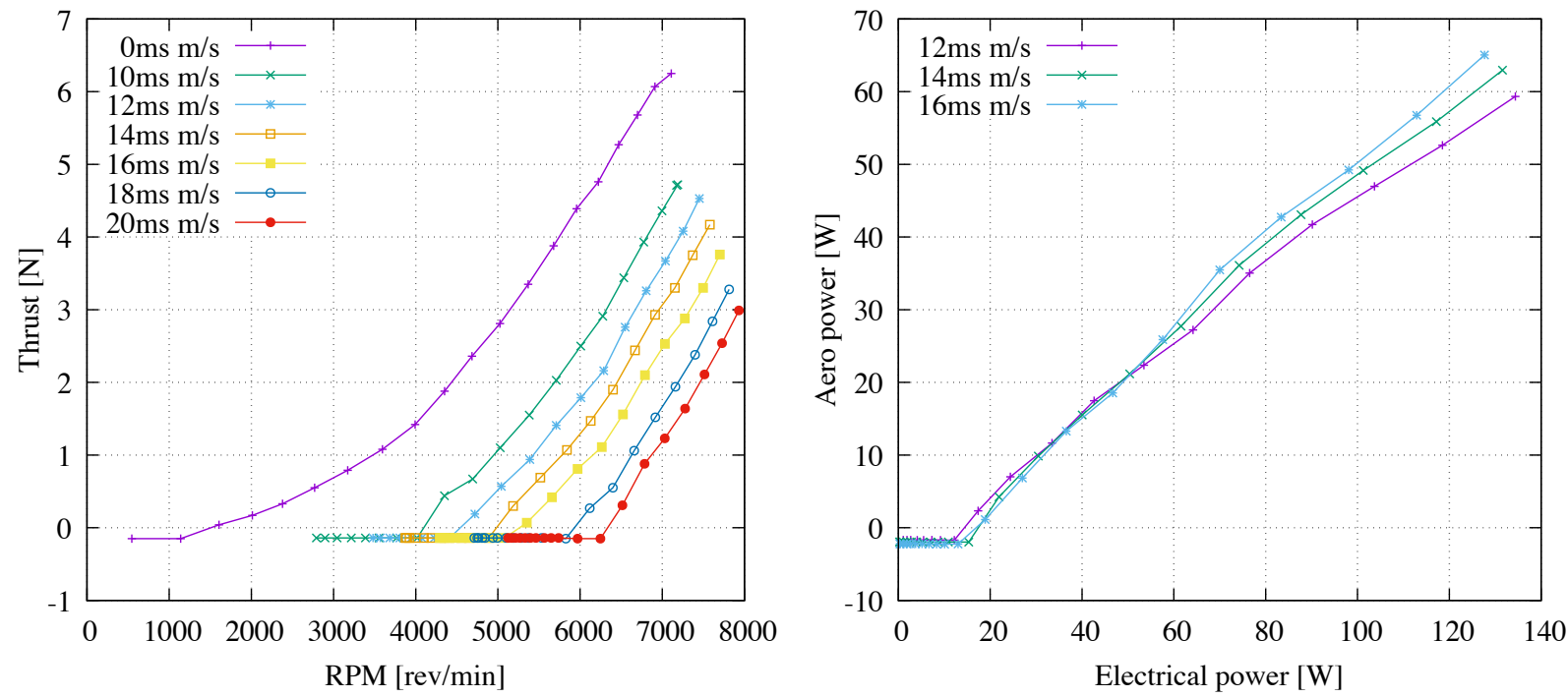

Figure 7. Thrust versus RPM at different airspeed from wind tunnel experiment, and aerodynamic propulsive power $(V \times T)$ versus electrical input power $(U \times i)$ for useful flight speeds.

The main interest for improving the aircraft identification is to find a simple relation 
between the propulsive power and a measurable parameter. The figure 7 shows this propulsive power versus the electrical power drown from the battery. The latter can be measured on-board easily from voltage and current sensors. As we can see, for the useful flight speeds from 12 to $16 \mathrm{~m} / \mathrm{s}$, there is a simple linear relation between propulsive output and electrical power input. This relation can be easily used for simulation or modeling of the aircraft, especially as it almost does not depend on the flight speed.

\section{On-Board Thrust Measurements}

Figure 8 shows the preliminary results obtained from the on-board thrust measurement mechanism. Presented flight starts with a catapult launch at around $200 \mathrm{~s}$ mark, then after some circling, four climb and glide tests flown in order to determine the lift to drag ratio and also the lift coefficient values by using the angle of attach sensor as explained in the previous section. These climb and descent phases are clearly visible from the altitude plot between $400 s$ and $700 s$. During the climbs, the increase on the thrust value can be seen, however a reduction on the maximum thrust also exists as the airspeed is increasing. Descent speeds varies because of different pitch angle settings. Each descent gets steeper in order to examine the characteristics of the aircraft at different flight speeds. Looking carefully, one can also see the drag of the propeller, which is kept closed but freewheeling without power, on the thrust measurements. The drag of the freewheeling propeller becomes more significant as the glide gets steeper at the last one.

The last part of the flight consists an almost level and unaccelerated cruise flight phase, where the airspeed and the altitude is kept constant. During the flight tests, there was a little bit wind which can be seen from the difference on the ground speed and air speed. The ground speed oscillates back and forth compared to the airspeed measurements that are obtained from the pitot-static tube. Taking an average of this cruise phase, the flight airspeed is found to be $16.7 \mathrm{~m} / \mathrm{s}$ and the averaged thrust during that phase is around $1.2 \mathrm{~N}$. The aerodynamic propulsive power is found to be around $20 \mathrm{~W}$. The corresponding electrical input power will be $50 \mathrm{~W}$ according to the linear relation that is shown in Figure 7. This is completely coherent with the current and voltage measurements. The system is too premature for having further detailed conclusions or discussions, however the results are very promising. On going work with the system includes a better calibration of the on-board thrust measurement mechanism, vibration isolation of the sensor in order to reduce the noise, converting the analog signal directly to digital at the output of the sensor, applying corrections coming from pitch angle change and axial accelerations during the flight, and implementing a better estimation filter by taking into account additional informations such as motor rotation speed. 

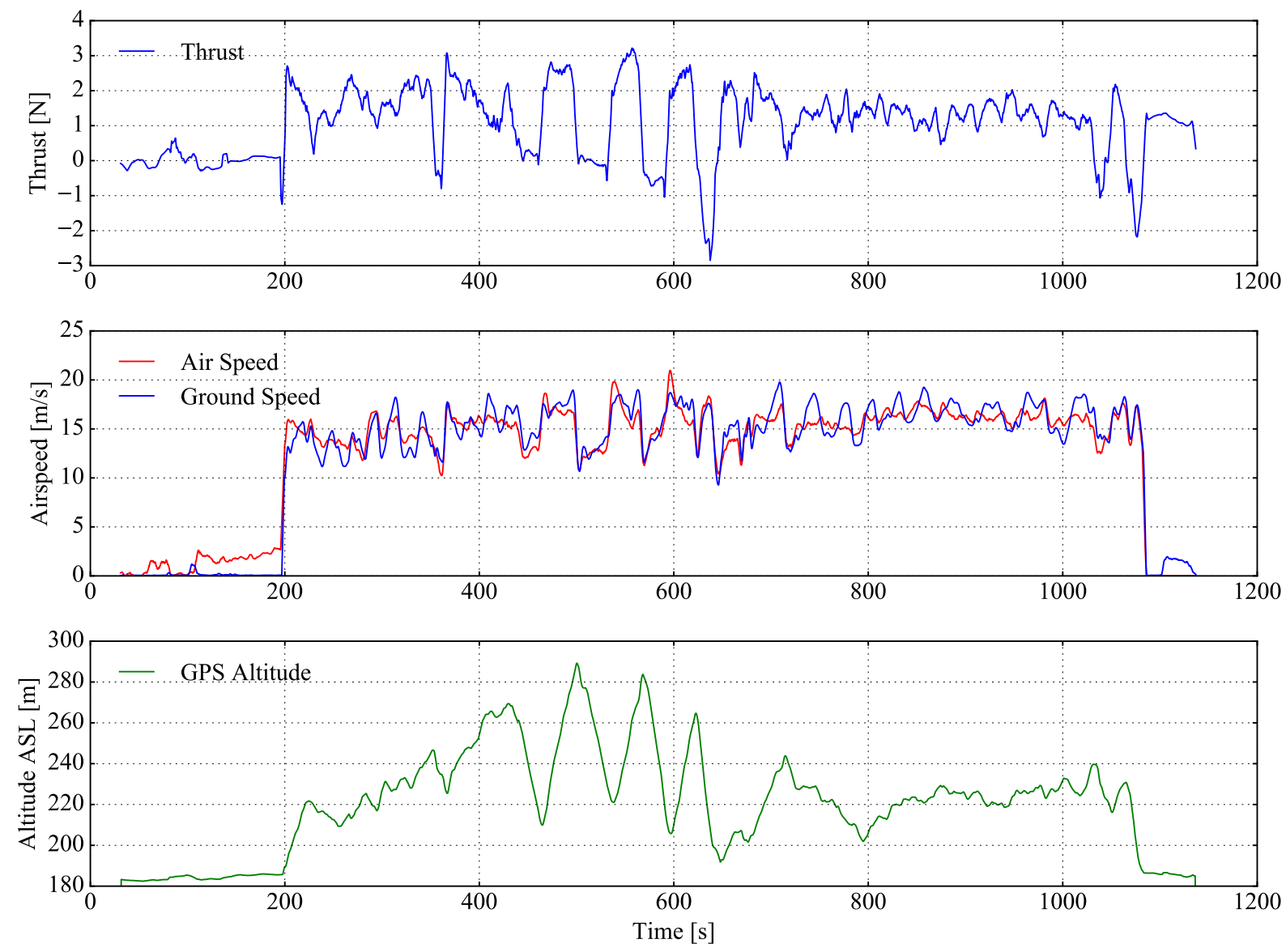

Figure 8. Preliminary flight results of the on-board thrust measurements are shown on the upper plot, with the airspeed and the ground speeds plotted in the middle, and finally the altitude information is shown on the bottom plot.

\section{Numerical Analyses}

The aerodynamics and flight dynamics of the aircraft are investigated by using open source programs, such as AVL and XFOIL from MIT.

\section{A. Reverse Engineering of the Aircraft Geometry}

The geometry of the aircraft is the main requirement for the numerical analysis programs. First the wing planform of the aircraft is extracted by using a digitalization program which requires high quality images of the geometry as an input. Once a known length is defined on the image, the program outputs the coordinates of the geometry. The wing chords at several spanwise locations have been extracted. The same procedure is repeated for the vertical surfaces and as well as to the wing airfoil section. It is assumed that the wing has a uniform airfoil section distribution along the span, so only the airfoil at the root section is digitalized for the following analyses. 


\section{B. Xfoil Results}

The wing section aerodynamics are analyzed by using XFOIL. ${ }^{9}$ The extracted geometry is shown on the bottom of Figure 9, which is a fairly thick airfoil (13\%) for such a small aircraft, but the main reason is probably structural strength. The aircraft is made up of Elapor foam and reinforced with carbon rods, the additional thickness helps maintaining the strength of the wing.
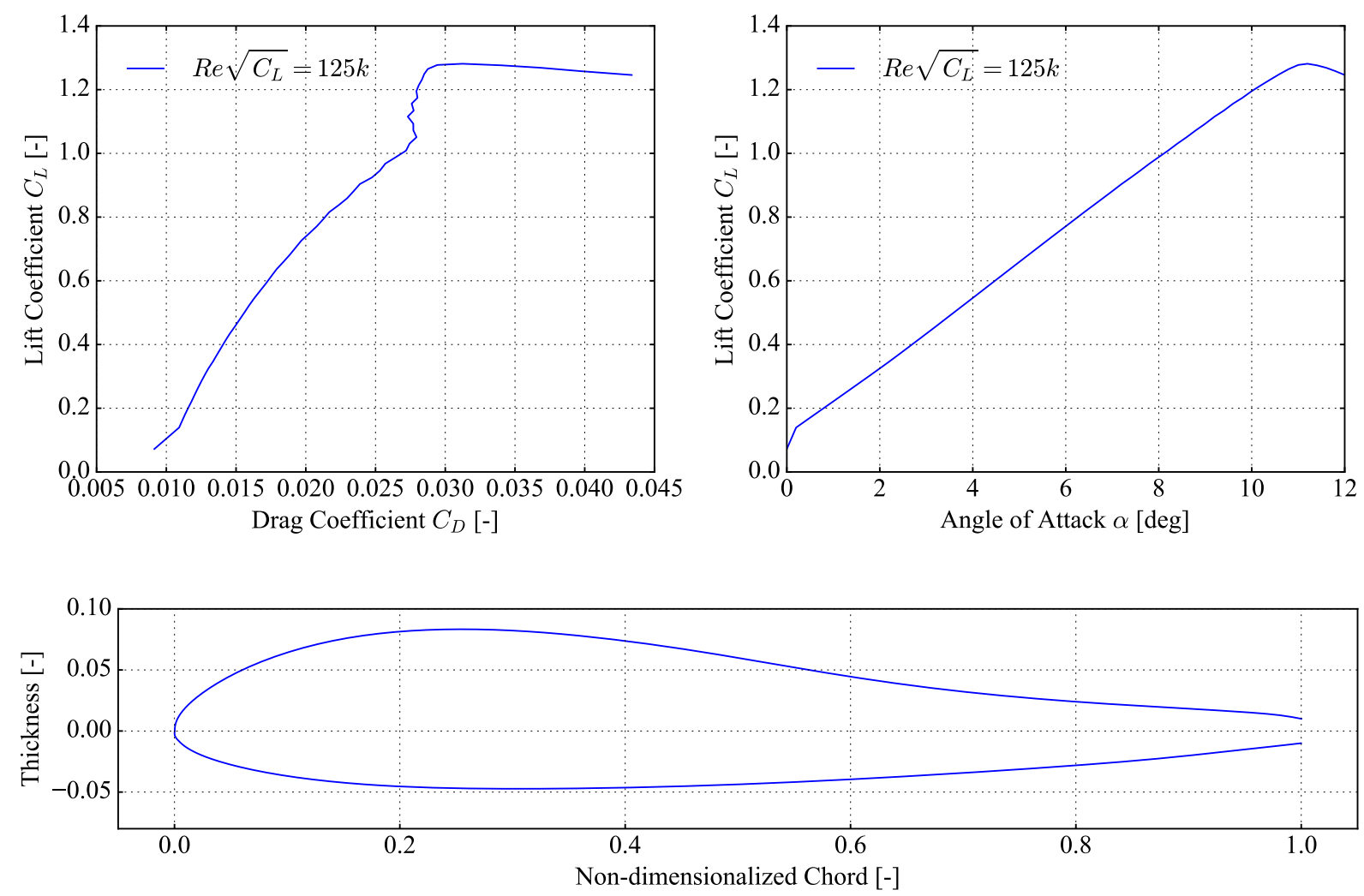

Figure 9. Digitalized airfoil geometry of the aircraft shown on the bottom with the XFOIL results of lift to drag and lift slope curve for $\operatorname{Re} \sqrt{C_{L}}=125 k$.

Required positive pitch up moment is generated by the airfoil, and not by twisting the wing towards wingtips. The advantage of this is visible over the full flight envelope speeds as the wing span efficiency stays nearly constant. However, the positive moment generating airfoil has a big laminar separation bubble that increases its drag. Nevertheless, the smooth lift slope, shown on the upper right of the Figure 9, is not effected from this bubble as it moves progressively with angle of attack changes. The fixed lift type polar analysis shown on the upper left side of the Figure 9 are done at $\operatorname{Re} \sqrt{C_{L}}=125 k$. 


\section{Vortex-Lattice Results}

Flight dynamics are modeled by using AVL from MIT, which uses a vortex-lattice method. As a modification to the existing program, the two-dimensional airfoil characteristics obtained from XFOIL is integrated as a database. This added database supplies the corresponding drag coefficient for each sectional lift coefficients that are calculated at local Reynolds number. Integration of the additional drag over the whole span gives the viscous drag of the wing.

Stability derivatives are calculated at equilibrium cruise flight condition at $14 \mathrm{~m} / \mathrm{s}$, which are shown in Table 3. The center of gravity is located at $X_{C G}=0.295 \mathrm{~m}$, which corresponds to a $8 \%$ of positive static margin.

\begin{tabular}{lccccccc} 
& $\alpha$ & $\beta$ & $\mathrm{p}$ & $\mathrm{q}$ & $\mathrm{r}$ & $\delta_{\text {elv }}$ & $\delta_{\text {ail }}$ \\
\hline$C_{L}$ & 3.9444 & 0.0 & 0.0 & 4.8198 & 0.0 & 0.016558 & 0.0 \\
$C_{Y}$ & 0.0 & -0.2708 & 0.01695 & 0.0 & 0.05003 & 0.0 & 0.000254 \\
$C_{D_{f f}}$ & - & - & - & - & - & 0.000409 & 0.0 \\
$e$ & - & - & - & - & - & 0.033728 & 0.0 \\
$C_{l}$ & 0.0 & 0.03319 & -0.4095 & 0.0 & 0.06203 & 0.0 & -0.001956 \\
$C_{m}$ & -0.3234 & 0.0 & 0.0 & -1.6834 & 0.0 & -0.0076 & 0.0 \\
$C_{n}$ & 0.0 & 0.0228 & -0.04139 & 0.0 & -0.01002 & 0.0 & -0.000126 \\
\hline
\end{tabular}

Table 3. Stability derivatives extracted from AVL program for the aircraft at $14 \mathrm{~m} / \mathrm{s}$ equilibrium cruise speed(All derivatives are in $\mathrm{rad}^{-1}$ or $(\mathrm{rad} / \mathrm{s})^{-1}$ except the control derivatives $\delta$ which are in $\mathrm{deg}^{-1}$ ).

\section{Comparison of the Numerical and Experimental Results}

The obtained quantities from the real flights which are listed on Table 2 are shown once more in comparison with their corresponding numerically estimated values in Table 4. Drag-1 represents the values obtained by the use of angle of attack sensor, and the Drag-2 represents the measurements done by using GPS distance and altitude information.

\begin{tabular}{lcccc} 
& $C_{L 0}$ & $C_{L \alpha}$ & $C_{D 0}$ & $C_{D k}$ \\
\hline Flight Tests (Lift) & -0.047 & 0.063 & & \\
Flight Tests (Drag-1) & & & 0.02313 & 0.1897 \\
Flight Tests (Drag-2) & & & 0.04353 & 0.2284 \\
Numerical & -0.028 & 0.069 & 0.02394 & 0.0606 \\
Reconfigured Numerical & & 0.057 & & \\
\hline
\end{tabular}

Table 4. Comparison of identified aerodynamic coefficients for lift and drag from flight tests and numerical analyses.

It can be seen that the $C_{L 0}$ coefficients obtained by flight test and numerical analysis are coherent with each other. The lift curve slope $C_{L \alpha}$ values also matches. Numerical es- 
timation method uses a finite differencing method in order to obtain the $C_{L \alpha}$, however the flight measurements obtain the $C_{L \alpha}$ through a curve fitting from several equilibrium points. These equilibrium points consists of all kind of additional control surface deflection related lift loss and drag addition which tends to reduce the $C_{L \alpha}$ of the aircraft, especially on a tailless configuration where the total pitching moment is equilibrated by the deflection of wing control surfaces that reduces the airfoil camber hence the lift at the given angle of attack. Unfortunately, with the method that is presented it is not easy to isolate this effect, but the numerical solutions can be reconfigured in a way to represent this phenomena for a better comparison. The reconfigured $C_{L \alpha}$ is obtained by analyzing two different flight speed equilibrium state and differencing $C_{L}$ and $\alpha$ values. The result is shown at the bottom of the Table 4, which is also different than the flight measurements, but more appropriate to compare with.

The drag coefficients found with the second method is over pessimistic mainly because of flight conditions. This method uses GPS ground speed in order to calculate the glide path $\gamma$ and the flight tests were done with a headwind which reduces the forward distance traveled by the aircraft thus the lift to drag ratio reduces significantly. The tests should not have been done in such conditions in the first place, however this clearly shows the disadvantage of this method thus is presented here.

The drag coefficients obtained from numerical analysis and flight tests with method-1 also differ from each other, being the one from flight tests are more pessimistic. Especially, the induced drag contribution differs a lot. One possible reason could be the freewheeling propeller which creates significant drag during the glide phases. Future tests will be done with a folding propeller in order to avoid this problem. For the moment, there is only a couple of glide and cruise phases that are used to calculate the coefficients, this is also a big source of error during calculation of the coefficients. More flight tests, with different total weight, have to be done in order to have a better understanding of this difference.

\section{Conclusion and Future Work}

Aerodynamic characterization of an off-the-shelf small tailless aircraft with a wing span of $1.3 \mathrm{~m}$ is presented. Autonomous level cruise flight and unpowered glide tests have been performed in order to extract aerodynamic characteristics of the aircraft. Digitalized geometry data of the aircraft is used to create the numerical mesh for vortex lattice calculations. The resultant stability derivatives are presented.

A rough flight dynamics model of the aircraft can be constructed with the presented results, however the significant difference between the numerical analysis and the experimental 
measurements on the drag coefficient shows the requirement of more flight tests and analysis.

Future and on-going work consists of flying with different total weight and wider speed envelope in order to increase the measurement range. A folding propeller will be used for the glide tests. The noise to signal ratio of the on-board thrust measurement has to be reduced in order to have usable measurements. Additional information such as the rotation speed of the propeller and the current consumption with the given flight air speed can be fused in order to have a better estimation of the on-board thrust. At the end, a complete model of the aircraft will be created and shared to be used by any project requiring a detailed model.

\section{Appendix}

As an addition to the aerodynamic coefficients and stability derivatives, it is useful to have the moments of inertia of the aircraft so that one can use the model in a simulator. The aircraft is hanged by two strings, at different orientations, as shown in Figure 10, and measurements performed by timing the oscillation period for each axis. The resultant moment of inertias are $I_{x x}=0.02471284 \mathrm{kgm}^{2}, I_{y y}=0.015835159 \mathrm{kgm}^{2}, I_{z z}=0.037424499 \mathrm{kgm}^{2}$ respectively.

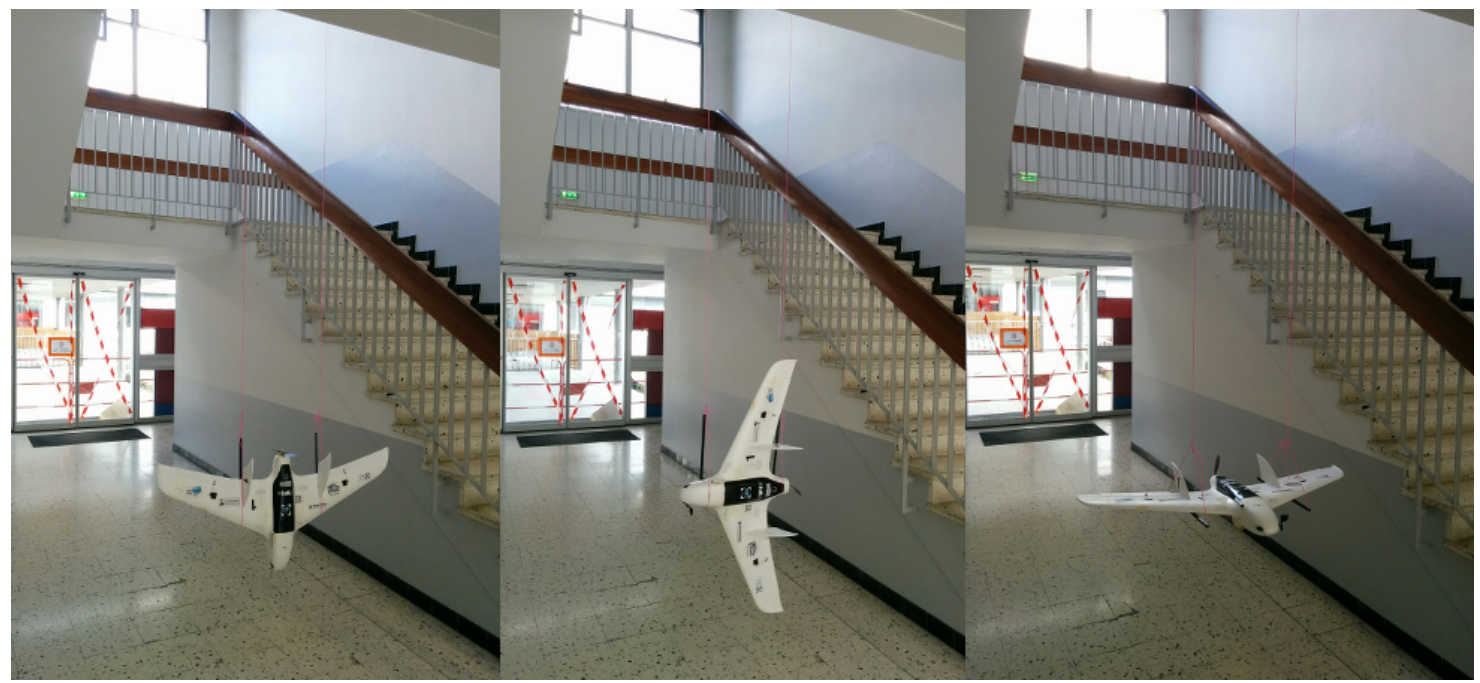

Figure 10. Moments of inertia measurements for each axis, $I_{x x}, I_{y y}, I_{z z}$.

\section{Acknowledgments}

The authors would like to thank you to Jean Philippe Condomines and Jean-Francois Erdelyi for their contribution on the experimental setup and flight tests.

\section{References}

\footnotetext{
${ }^{1}$ Bronz, M. and Hattenberger, G., "Design of A High-Performance Tailless MAV Through Planform Optimization," 33rd AIAA Applied Aerodynamics Conference, AIAA, 2015, pp. eISBN-978.

${ }^{2}$ Nio, J., Mitrache, F., Cosyn, P., and Keyser, R. D., "Model Identification of a Micro Air Vehicle," Journal of Bionic Engineering, Vol. 4, No. 4, 2007, pp. 227 - 236.
} 
${ }^{3}$ Valavanis, K. P. and Vachtsevanos, G. J., Handbook of Unmanned Aerial Vehicles, chap. UAV Modeling, Simulation, Estimation, and Identification: Introduction, Springer Netherlands, Dordrecht, 2015, pp. 12151216.

${ }^{4}$ Simsek, O. and Tekinalp, O., "System Identification and Handling Quality Analysis of a UAV from Flight Test Data," AIAA Atmospheric Flight Mechanics Conference, AIAA SciTech, AIAA 2015, 2015.

${ }^{5}$ Edwards, D., "Performance Testing of RNR's SBXC Using a Piccolo Autopilotd," Tech. rep., 2007.

${ }^{6}$ Brisset, P., Drouin, A., Gorraz, M., Huard, P.-S., and Tyler, J., "The paparazzi solution," MAV2006, Sandestin, Florida, 2006.

${ }^{7}$ Hattenberger, G., Bronz, M., and Gorraz, M., "Using the Paparazzi UAV System for Scientific Research," IMAV 2014, International Micro Air Vehicle Conference and Competition 2014, Delft, Netherlands, Aug. 2014, pp. pp 247-252.

${ }^{8}$ Drela, M., "First-Order DC Electric Motor Model," Tech. rep., MIT, Aero and Astro, February 2007.

${ }^{9}$ Drela, M., "An Analysis and Design System for Low Reynolds Number Airfoils," Conference on Low Reynolds Number Airfoil Aerodynamics, edited by U. of Notre Dame, June 1989. 